\title{
Isn't it Ironic? An Analysis on the Elaboration of Ironic Sentences with ERPs
}

\author{
M. Balconi* and S. Amenta
}

Department of Psychology, Catholic University of Milan, Italy

\begin{abstract}
Although frequent in our everyday conversations, irony is a complex pragmatic phenomenon involving specific linguistic, communicative and cognitive abilities in order to be fully understood. In this study we examined the pragmatic comprehension of ironical and non ironical language by analysing event-related potentials (ERPs) of irony decoding process. We asked 12 subjects to listen to 240 sentences with a counterfactual vs. non-counterfactual content and spoken with ironical vs. neutral prosody. ERPs morphological analysis showed a negative deflection peaking in central-frontal and parietal areas at about $460 \mathrm{~ms}$ post stimulus onset (N400) for all the conditions. Statistical analyses applied to peak amplitudes showed no statistically significant differences between the conditions as a function of the type of sentence (ironical vs. non ironical) and the content of ironical sentences (counterfactual vs. non counterfactual). An increase of N400 related to ironical sentences was nonetheless observed. The absence of an N400 effect may indicate that irony is not treated as a semantic anomaly, although, the observed differences in amplitude could be probably attributed to a higher requirement for the cognitive system in order to integrate contrasting and complex lexical, prosodic and contextual cues.
\end{abstract}

\section{INTRODUCTION: IRONY BETWEEN PRAGMATICS AND PSYCHOLINGUISTICS}

Although frequent in our everyday conversations, irony remains a complex communicative and pragmatic phenomenon whose correct decoding requires specific linguistic, communicative and cognitive abilities. While trying to explain how irony is used by speakers, linguistics and pragmatics elaborated different theories exploring the nature of ironic communication and of its production and comprehension processes. Within these frameworks, irony has been considered a form of semantic anomaly $[1,2]$ or as a pragmatic construct involving forms of pragmatic insincerity [3], pretense [4], echoic elements [5] or context-inappropriateness [6]; or again it has been considered as a form of indirect negation [7, 8]. On a cognitive level it has been conceptualized as a form of thought [9-11] involving different grades of contrast between linguistic representation and the reality domain it refers to [12] Finally, with a communicative approach, we can consider irony not as a semantic or pragmatic anomaly, but as a form of communication involving different levels of representation and complex communicative intentions ([13, 14], for analytic review of principal theories on irony).

Generally irony can be defined as a pragmatic phenomenon where a gap exists between what is said and what is meant by the speaker. This gap is not necessarily a form of counterfactuality, in fact, Kreuz demonstrated [15] that saying something patently false is only one cue of irony, but not a sufficient one. Some examples of non counterfactual irony are represented by the case of understatements and hyperboles, those particular forms of language where a situation is

*Address correspondence to this author at the Center for Communication Psychology, Department of Psychology, Catholic University, Largo Gemelli, 1, 20123 Milan, Italy; Tel: +39-2-7234.2586; Fax: +39-27234.2769/2280; E-mail: michela.balconi@unicatt.it described in intermediate terms between its opposite and its reality [16] or, again, the case of true statements that can be appropriate but not fully relevant in the situation [17, 6]. These two cases are frequent between ironic remarks. Futhrmore, some comments such as questions, offerings, overpolite requests or expressives, could be ironic even if they cannot be evaluated in terms of truth conditions. In order to explain the ironicity conveyed by these expressions, Kumon-Nakamura and colleagues [3] appealed to the construct of pragmatic insincerity that is an expression that violates felicity conditions more than truth conditions $[2,18$, 19]. However, pragmatic insincerity cannot be considered a sufficient cue for irony as well. Other cues have been identified in the callbacks to expectations, whether explicit or implicit $[4,20,21]$, norms or shared beliefs $[17,10]$. Finally extralinguistic cues, such as, vocal and prosodic profile or facial mimics, have been considered important on a communicative level $[15,22,23]$.

In order to decode these cues and consequently understand the communicative intention involved in such a complex pragmatic phenomenon, it is necessary to apply different meta-representational, meta-linguistic and pragmatic abilities. Thence the complexity of irony is apparent and it is not surprising that different theories have been elaborated to explain what irony is and how it is understood by decoders.

This last question - relative to irony comprehension -, in particular, has been the focus of psycholinguistics investigations. In this perspective, three main models of language processing tried to explain irony comprehension processes formulating three different hypotheses on the basis of the relation between lexical access and contextual information of ironic statements: the sequential model elaborated by the Standard Pragmatic View [1, 2]; the Parallel Access Models $[24,25]$; and finally, the Direct Access View [9, 26].

According to the Standard Pragmatic View, irony can be considered a violation of conversational maxims, in particu- 
lar of the quality (truthfulness) one. It is thus necessary, in order to understand an ironic meaning to process, at first, the literal meaning of the ironic statement, then test this meaning against the context and, whether the violation of conversational maxims is detected, to look for an alternative - nonliteral - meaning. The process to retrieve the intended meaning involves extra-inferential processes named "conversational implicatures". Only at the end of this process the incoherence is solved and the intended meaning reconstructed [27, 19]. This process is supposed to require an extra-effort, therefore extra-time, to reach the right interpretation. This standard model has been actually disconfirmed by different empirical studies which found that, in particular cases, response time (RT) to ironies are not slower than RT to literal statements [9, 26, 28-31].

The Parallel Access Model, on the contrary, suggests that both the literal and the nonliteral interpretation of an utterance are always processed. Two main models can be brought back to this general model: the Parallel Race Model [24] and the Graded Salience Hypothesis [25].

Long and Graesser [24] assumed that, in ironic communication, a discrepancy exists between what is expected and what actually occurs. In particular, within an ironic statement, what is expected is the intended ironic meaning while what occurs is the literal meaning. Following this hypothesis, the context (background, linguistic, conversational and social) plays a crucial role in irony comprehension processes either allowing comprehension to occur after some discrepancy is recognized or biasing the interpretation early on. Either way both literal and ironic meaning are simultaneously accessed and concurrently processed, and they both participate in ironic meaning construction. Dews and Winner [32, 33 ] tested this model showing that deriving an ironic interpretation involves some recognition (conscious or unconscious) of the discrepancy between literal and ironic meaning. If one only recognizes the intended meaning of an ironic utterance without noticing at some level what was literally said, one has not fully understood irony. Anyway Dews and Winner concludes that the entire literal meaning need not be processed before the intended meaning is accessed, as was the case of standard pragmatics, since multiple meanings can be processed simultaneously.

On the other side, Giora [25, 29] suggests that the initial elaboration of literal or nonliteral meanings is linked to meaning salience. To be salient a meaning should be coded in the mental lexicon and that happens when it is familiar, frequent, conventional and prototypical. When two or more meanings are salient, they should be accessed in parallel. According to this model, irony elaboration is a matter of salience more than of context [34]. Giora distinguishes between familiar (conventional) and non familiar (non conventional) ironies on the basis of salience and aptness and supposes that non lexical contextual information should not affect initial meaning activation: salient lexical meaning (literal) of non familiar ironies is the only one instantly activated also in ironically biased context, even though it is incompatible with contextual information. On the contrary, the salient literal meaning of familiar ironies is available in ironically biased contexts in spite of a mismatch with contextual information. In sum, irony comprehension seems to be a function of meaning salience and not of context [34].
A third approach to irony comprehension proposes that, under some particular circumstances, ironic meaning is directly accessed [26, 35]. Gibbs proposes that in a context offering enough ironic cues, non literal interpretation of a statement is direct and automatic with no need to compute the literal inconsistent interpretation. That could happen because in a high constraining context, a nonliteral interpretation is conventional, so the elaboration of nonconventional literal meaning is optional and the listener does not have to fully elaborate the literal meaning and its incongruity. This hypothesis has been tested through reading time paradigms, whose basic assumption is that reading times of sentences could be suggestive of the initial comprehension processes. Reading time of ironic non conventional utterances showed they require extra effort to elaborate in comparison to their literal conventional interpretation, whereas this is not the case of conventional ironies [30, 33, 36].

As we have seen, empirical findings of behavioural studies, supporting or opposing these models, are controversial, therefore the question about how irony is processed remains open. More recently, neuropsychological technologies have been applied to figurative language comprehension. In the following paragraph we will examine some of the findings these technologies provided when applied to irony studies.

\section{EMPIRICAL FINDINGS FROM ELECTROPHYSIO- LOGY: APPLYING ERPS TO IRONY INVESTIGA- TION}

Event-related potentials (ERPs) have been successfully used in psycholinguistic studies on literal and figurative language ([37, 38] for a review) with interesting results that, together with reading time and lexical decision paradigms, helped to understand complex pragmatic phenomenon such as metaphor [39-42] or humour [42], and only recently have been applied to irony studies [43-45].

ERPs are a measure characterized by high temporal definition and provide intrinsic indexes of cognitive processes [46]. The most known index of semantic integration is N400, a negative, central-parietal deflection, that peaks around 400 $\mathrm{ms}$ from stimulus onset [47]. N400 is an amodal index elicited by any stimulus with a semantic valence and which amplitude is directly proportional to the effort requested by the integration process of the stimulus it is related to. It is generally considered as a measure of the difficulty for the retrieval and integration of semantic information related to an incongruous or ambiguous word in a context [47, 48] N400 has been proved to be sensitive to ambiguous words in context, to semantic and pragmatics anomalies and to unexpected words or sentence finals [48-53].

In figurative language studies, N400 has been used as an index to study qualitative and quantitative differences between literal and non literal language. Metaphor studies found generally an increase of the N400 amplitude associated with metaphoric expression in comparison to literal sentences. Coulson and Van Petten [39] compared literal sentences to a literal mapping condition and to metaphoric sentences finding a progressive increasing of N400 peak amplitudes from literal to metaphoric expressions. The authors interpreted these results as a gradient of complexity in sentence decoding in the three conditions. Coulson and Van Petten results seem to confirm Pynte et collaborators [49] 
findings, who previously reported progressive variations in N400 intensity across literal sentences, conventional metaphors and novel metaphors. Anyway, the identification by Coulson and Van Petten of an intermediate condition, namely the literal mapping, between literal and metaphoric sentences seemed to indicate that elaboration processes literal and metaphoric sentences do not qualitatively differ, since the processes seem to share the same mechanism of conceptual integration. In addition, Pynte, suggested other factors could concur in N400 modulation and these are context and familiarity, the first being fundamental since it could frame the sentence biasing the interpretation process.

N400 sensitivity to contextual information, renders it a valid index to explore the process of irony comprehension and to test the pragmatic models of irony processing.

A recent study [43] used ERPs to assess the effects of cognitive elaboration strategies (analytic versus holistic) on irony comprehension. The results of the study show that in the holistic condition, where subjects were asked to look for the global sense of the proposed sentence, each category tested (literal vs. ironical vs. nonsensical) generate a negativity, analogue to the N400 component, mainly in the left frontal-central zone. Significant differences were observed in the literal condition when compared to both the ironical category and the nonsensical category. Authors concluded that the differences observed in the N400 for both the nonsensical and the ironical condition compared to the literal condition could be due, in the first case to the semantic incongruity of the nonsensical stimulus, instead, in the second case, the increase of the N400 could be attributed to the lack of con-

Pragmatic model Irony elaboration hypothesis textual information favouring the ironical comprehension.

An opposite result was found by another study [54] that tried to assess the influence of prosody on ironic comprehension by manipulating both the context and the paralinguistic components of ironic expressions. Results of this study showed no difference in the N400 amplitude due to prosody. These findings seem to confirm that, when sufficient contextual information is present, ironical elaboration is easier at least in the first phases (no N400 effect appeared in a prosodically enriched context).

\section{OBJECTIVES AND HYPOTHESES}

Main aim of the present study is to explain how ironic sentences are processed, testing pragmatic models of irony comprehension through the ERP methodology.

In particular, in the present study we intend to explore the influence of the prosodic cues on the initial phases of irony comprehension process where little contextual information is given. We are interested in better understanding the cognitive and neuropsychological mechanisms involved in early phases of the comprehension process of ironic statements. Therefore our analyses will focus on the 300-400 time window.

We hypothesize that if irony is perceived and categorized as a semantic incongruity, therefore we should observe an ampler N400 (from now hence: N400 effect). On the contrary, if irony is immediately recognized (that is the ironic remark is not understood as semantically incongruous), therefore no N400 effect should be present.

Tracking it down to a classical pragmatic hypothesis we

\begin{tabular}{|c|c|c|}
\hline $\begin{array}{l}\text { Standard } \\
\text { Pragmatics } \\
\text { (Grice, Searle) }\end{array}$ & $\begin{array}{l}\text { - priority of lexical semantic information } \\
\text { - ironic meaning is derived after literal } \\
\text { meaning has been rejected as the intended } \\
\text { meaning }\end{array}$ & - N400 increase \\
\hline $\begin{array}{l}\text { Parallel Access } \\
\text { Models: }\end{array}$ & & \\
\hline $\begin{array}{l}\text { Parallel Race } \\
\text { (Long \& } \\
\text { Graesser; Dews \& } \\
\text { Winner) }\end{array}$ & $\begin{array}{l}\text { - lexical and contextual meanings are both } \\
\text { activated and concurrently processed } \\
\text { - literal meaning is essential to understand } \\
\text { ironic meaning }\end{array}$ & $\begin{array}{ll}\text { - } & \text { No N400 increase } \\
\text { - Eventually: later ERP effects } \\
\text { signalling closure processes }\end{array}$ \\
\hline $\begin{array}{l}\text { Graded Salience } \\
\text { (Giora) }\end{array}$ & $\begin{array}{l}\text { - priority of salient meaning over contextual } \\
\text { fit } \\
\text { - familiar ironies have two salient meanings } \\
\text { (literal and ironic): they are both activated } \\
\text { and processed } \\
\text { - non familiar ironies have one salient } \\
\text { meaning (literal): ironic meaning is derived } \\
\text { after lexical meaning has been rejected }\end{array}$ & $\begin{array}{ll}\text { - } & \text { No N400 increase for familiar } \\
\text { ironies } \\
\text { - }\end{array}$ \\
\hline $\begin{array}{l}\text { Direct Access } \\
\text { (Gibbs) }\end{array}$ & $\begin{array}{ll}\text { - } & \text { priority of contextual information } \\
\text { - } & \text { early interaction between lexical-semantic } \\
\text { information and contextual information to } \\
\text { select context congruent meaning } \\
\text { - } & \text { ironic meaning is directly accessed }\end{array}$ & - No N400 increase \\
\hline
\end{tabular}

Fig. (1). Pragmatic models and expected ERPs effects. 
can say that if, as standard pragmatics asserts, ironical meaning is derived after the literal meaning is processed and rejected, therefore an N400 effect should be present. On the contrary, if the ironical meaning is concurrently processed together with literal meaning or directly accessed, as Parallel Model and Direct Access view argue, no N400 effect should be present. Fig. (1) resumes the principal pragmatic models on irony elaboration and their related ERP components.

\section{MATERIALS AND METHODOLOGY}

\section{Participants}

12 right-handed university students (9 women, 3 men; mean age $=23$ years, $\mathrm{SD}=0,56)$ all enrolled in the Psychology Faculty of the Catholic University of Milan participated to the study. All the participants declared not to have personal or family antecedents of neurological or psychiatric diseases. They gave oral informed consent and they were not paid for their participation.

\section{Stimuli}

Stimuli consisted in a set of literal and ironic sentences presented in auditory modality. All the statements were of the type " $\mathrm{X}$ is $\mathrm{Y}$ ", where the first part was the same concrete noun in each condition, while the ending could be literal (congruent with neutral prosody) or ironic (congruent with ironic prosody or incongruent with ironic prosody). So the three experimental conditions can be exemplified as follows:

a) An insult is an affront (neutral tone of voice). Literal.

b) An insult is a pleasantry (ironic tone of voice). Counterfactual irony.

c) An insult is an abuse (ironic tone of voice). Non counterfactual irony.

There were a hundred sentences of each type. The stimuli were tested in a pre-experimental phase (12 participants) on a 5-points Likert-type scale for familiarity, truthfulness and concreateness. Items not reaching 3 on each scale were rejected.

Finally, a professional actor was asked to perform the literal sentences with a plain tone of voice and the ironic sentences with an ironic prosody $[22,23,55]$, while we were recording his voice. A new pre-experimental test (12 participants) was conducted to assess on a 5-points Likert-type scale the ironic level of the auditory stimuli. Ironic stimuli not reaching 3 on the scale were rejected. At the end of the pre-experimental phase, 240 stimuli were considered for the research.

The stimuli, 80 for each condition, were then randomly assigned to three batteries so each version of every sentence was presented only once in each pool. Every statement was followed by an interval (ISI) of 3 seconds of silence. Sequences were also split in two sub-batteries so not to overload subjects' cognitive system. Subjects were randomly divided in groups of four, then assigned to one battery.

\section{Procedure}

The experiment took place at the Laboratory of Cognitive Psychology of Catholic University of Milan. Subjects were invited to take a seat on a comfortable chair in a darkened room which had been tested for electromagnetic interference. They were informed on the scope of the experiment, that is language comprehension processes, and about the experimental procedure. After we placed the electrodes (see below) on the participants'scalp, they were asked to keep still, in front of a computer monitor, to stare at a fixation point presented in the centre of the screen and to listen carefully to the stimuli. (NeuroScan STIM 2.2)

First the participants were familiarized with the procedure with a sequence consisting in 12 stimuli, three for every type of sentence. After a short pause, subjects were presented with the experimental battery. We explicitly ask the subjects to listen to the stimuli and to try to understand what the speaker meant by what he was saying. After the experiment, participants were asked to express some evaluations on the stimuli previously heard. Stimuli were tested on a 5points Likert-type scale for literality and ironicity.

\section{EEG and ERPs Recording Techniques}

The participants wore an electrocap which measured a continuous EEG while they performed the task. The EEG data were sampled by an amplifier (NeuroScan SYNAMP 4.2) for $1.000 \mathrm{~ms}$ from stimulus onset (100-ms baseline) at $500 \mathrm{~Hz}$ using an on-line $0.1-50 \mathrm{~Hz}$ band pass filter. We recorded the EEG from $14 \mathrm{Ag} / \mathrm{AgCl}$ electrodes that were all referenced to the earlobes. We recorded the vertical electrooculogram (EOG) from bipolar electrodes above and at the outer canthus of the right eye. The 14 scalp sites used according to the international 10-20 system [56] were: (a) four midline, $\mathrm{Fz}, \mathrm{Cz}, \mathrm{Pz}$ and $\mathrm{Oz}$; (b) right or left frontal, F4 and F3; (c) central, C4 and C3; (d) temporal, T4 and T3; (e) parietal, $\mathrm{P} 4$ and $\mathrm{P} 3$; and (f) occipital, $\mathrm{O} 2$ and $\mathrm{O} 1$. A ground electrode was placed on the forehead. Electrodes impedances were kept below $50 \mathrm{~K} \Omega$. The EEG was then filtered off-line using a digital 1-40 Hz band pass filter. ERPs were timelocked to the onset of the last word of the sentence (target word). Peak amplitude measurement was quantified relative to $100 \mathrm{~ms}$ pre-stimulus.

\section{DATA ANALYSES}

\section{ERPs Analysis}

We used then an artefact rejection procedure based on the electrooculogram (EOG) analysis to discharge possibly artifacted EEG segments (i.e. trials invalidated by interferences such as blinks). We rejected $13 \%$ epochs for EOG or muscular artifacts. For the same reason, 2 subjects (both female) were eliminated. We computed the averaged evoked responses (offline) for each participant. No subject AVG was calculated with less of 18 stimuli. Then we computed three waves elicited by (a) literal sentences, (b) counterfactual ironic sentences and (c) non counterfactual ironic sentences. We then proceeded with morphological analysis.

First step of our analysis consisted in a qualitative exploration of the wave profiles in search of significant variations relative to stimulus presentation in the three conditions. We combined a visual exploration of the profiles with a computerized peak detection (Edit Software NeuroScan 4.2) in order to find minimum and maximum values of peak intensity. 
The analyses showed in each condition a first negative deflection peaking around $350 \mathrm{~ms}$ followed by a second negative deflection peaking about $460 \mathrm{~ms}$ from stimulus onset (N400) (see Fig. 2). We then obtained a grand mean average across participants for two temporal windows, 300-400 $\mathrm{ms}$ and $400-500 \mathrm{~ms}$ and computed minimum peak amplitude for both windows. For statistical analyses we focused only on the N400 time window.

\section{Peak Amplitudes Analysis}

A repeated measure ANOVA was applied to our data with three within-subjects factors $(2 \times 3 \times 5$ design): hemisphere (right vs left), type of sentence (literal vs. counterfactual irony vs. non counterfactual irony), cerebral area (frontal vs. central vs. temporal vs. parietal vs. occipital). A Greenhouse-Geisser correction was applied. Results show no statistically significant effects of type $\left(F_{(2,9)}=2,704, p=.125\right)$,
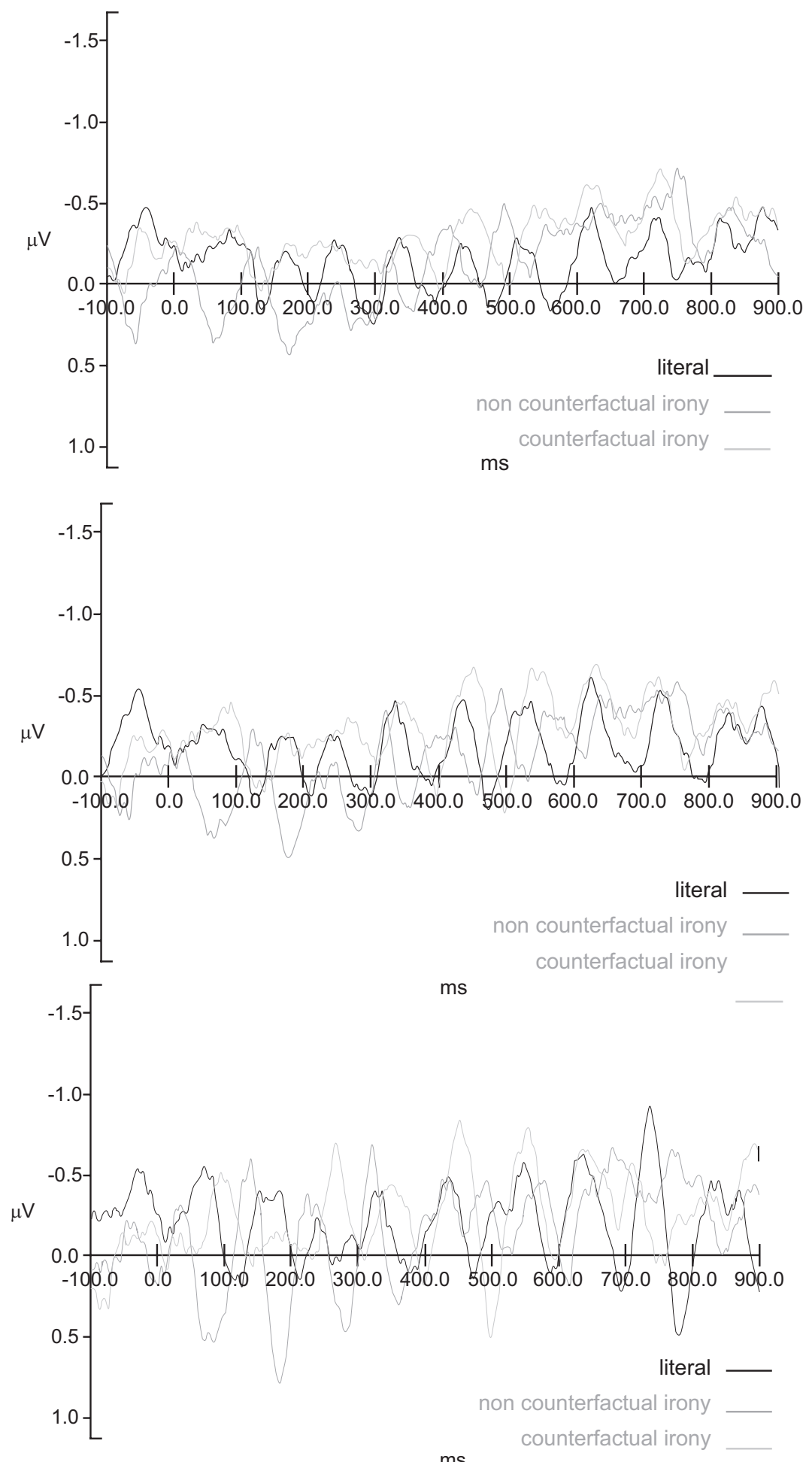

Fig. (2). Average for counterfactual irony, non counterfactual irony and literality on $\mathrm{Fz}(\mathbf{a}), \mathrm{Cz}(\mathbf{b})$ and $\mathrm{Pz}$. (c). 
hemisphere $\left(\mathrm{F}_{(1,9)}=.438, p=.524\right)$ or area $\left(\mathrm{F}_{(4,9)}=1,831\right.$, $p=.197)$. Besides no significant interaction effect was found.

From descriptive analyses emerged an interesting trend relative to the difference in mean amplitude for the three conditions. In particular we observed that counterfactual and non counterfactual ironic statements showed a mean amplitude of $-.188 \mu \mathrm{V}$ and -.187 respectively while literal statements elicited a less intense N400 component with maximum peak of -.143 . Left hemisphere seemed to be the more involved in counterfactual irony processing (mean amplitudes: left $=-.195$; right $=.180$ ) while no substantial differences were observed between the hemispheres in the other conditions. Finally, the N400 component reached maximum amplitudes in the frontal (mean amplitude $\mathrm{F}=-.192$ ) and central (mean amplitude $\mathrm{C}=-.189$ ) areas and in parietal regions (mean amplitude $\mathrm{P}=.171$ ).

Fig. (3) summarize our results relative to N400 peak amplitude in the three conditions, while Fig. (4) shows N400 amplitudes in different cortical areas.

\section{DISCUSSION}

Classical pragmatics models discussed whether irony should be considered as a semantic anomaly or as a complex phenomenon whose meanings originates in the early integration of linguistic and contextual information. In the first case, as standard pragmatics argues, ironic meaning is the result of three distinct operations: linguistic meaning processing, semantic incongruity detection and conversational implicatures generation. An ERP index of this incongruity resolution process should be an increased N400, since this component has been associated to the detection of a semantic incongruity likely due to the individuation of violations of conversational rules. In the second case, instead, linguistic and contextual information interact early on in ironic meaning construction, therefore no incongruity is relieved and no N400 effect should be apparent.

Our analysis showed no statistically relevant N400 effect relative to irony elaboration with respect of literal utterances.
This result, in line with previous studies [54], which found no N400 effect relative to ironic processing when sufficient contextual information relative to extra-linguistic components is given, seems to rule out standard pragmatic model as a valid elaboration hypothesis. Besides, the results seem to confirm the hypothesis that the N400 modulations is a function of contextual and especially nonverbal information $[43$, 57]. In this sense we are allowed to accept that irony is not a semantic anomaly and that ironic meaning is not interpreted after an incongruity detection and resolution process has taken place. On the contrary, we can suppose that, when enough contextual information is given - such as vocal cues -, ironic meaning elaboration starts early on in sentence processing.

Interesting it seems to be also the lack of a statistically significant difference between the two kinds of irony involved, that is counterfactual vs. non-counterfactual. This result, together with the previous one, confirms that irony is not treated as a semantic anomaly, as false (hence counterfactual sentences are) and suggests that ironic meaning is derived in a global meaning retrieval process where counterfactual content could serve as an index of an ironic intention $[12,58,59]$.

The absence of a statistically relevant effect due to ironical stimulation leaves two hypotheses open: the Parallel Access and the Direct Access. The last approach assumes that ironical meaning should be as easy to elaborate as nonironical meaning, since local and global information interact early on in the meaning selection process. Nevertheless, our data showed a tendency toward an increase in the N400 amplitude in ironic statements elaboration in comparison to literal statements processing that seems not to confirm at all this hypothesis. Furthermore we found a substantial modification of the N400 component relative to ironic stimuli, with an increasing in the frontal-central areas. We will discuss the two tendencies separately.

First, the increase of the N400 amplitude for ironic stimuli (both conditions) suggests that ironic elaboration required

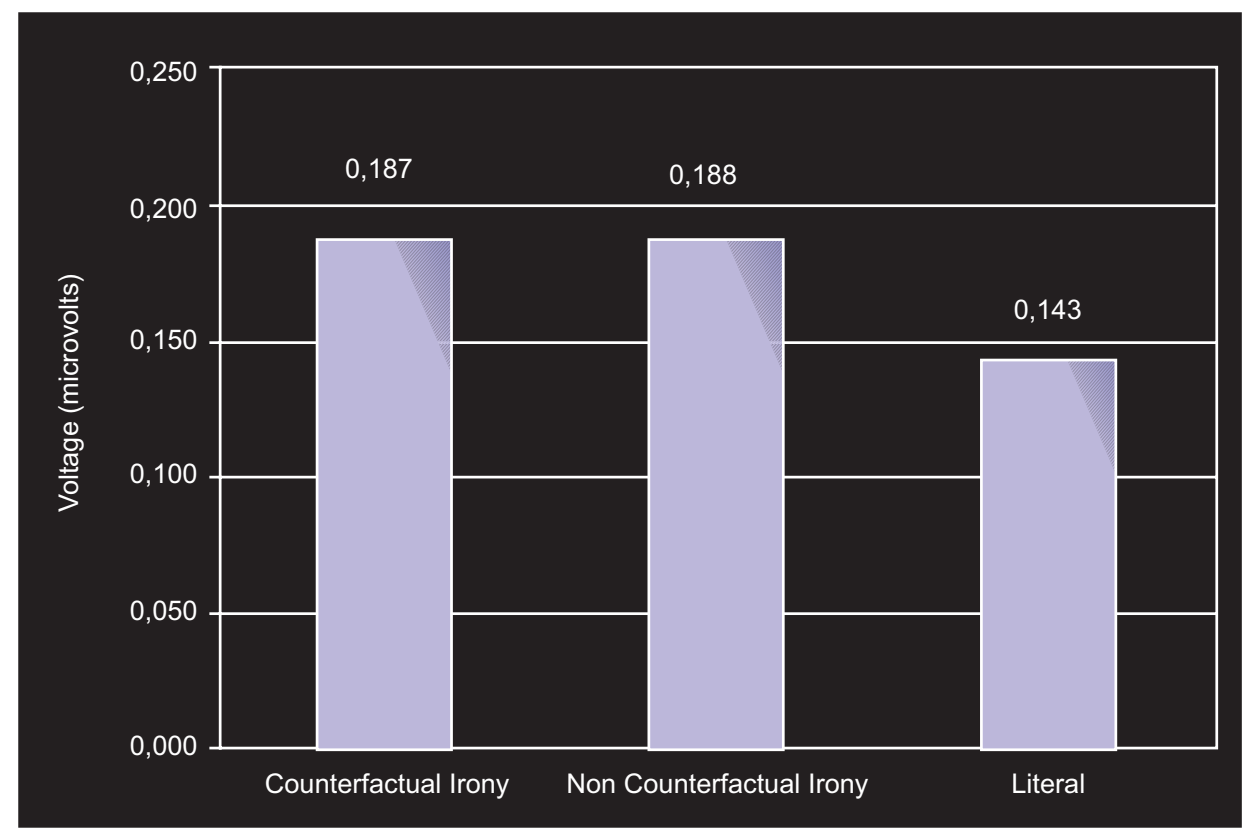

Fig. (3). N400 peak amplitude as a function of the type of sentence. 

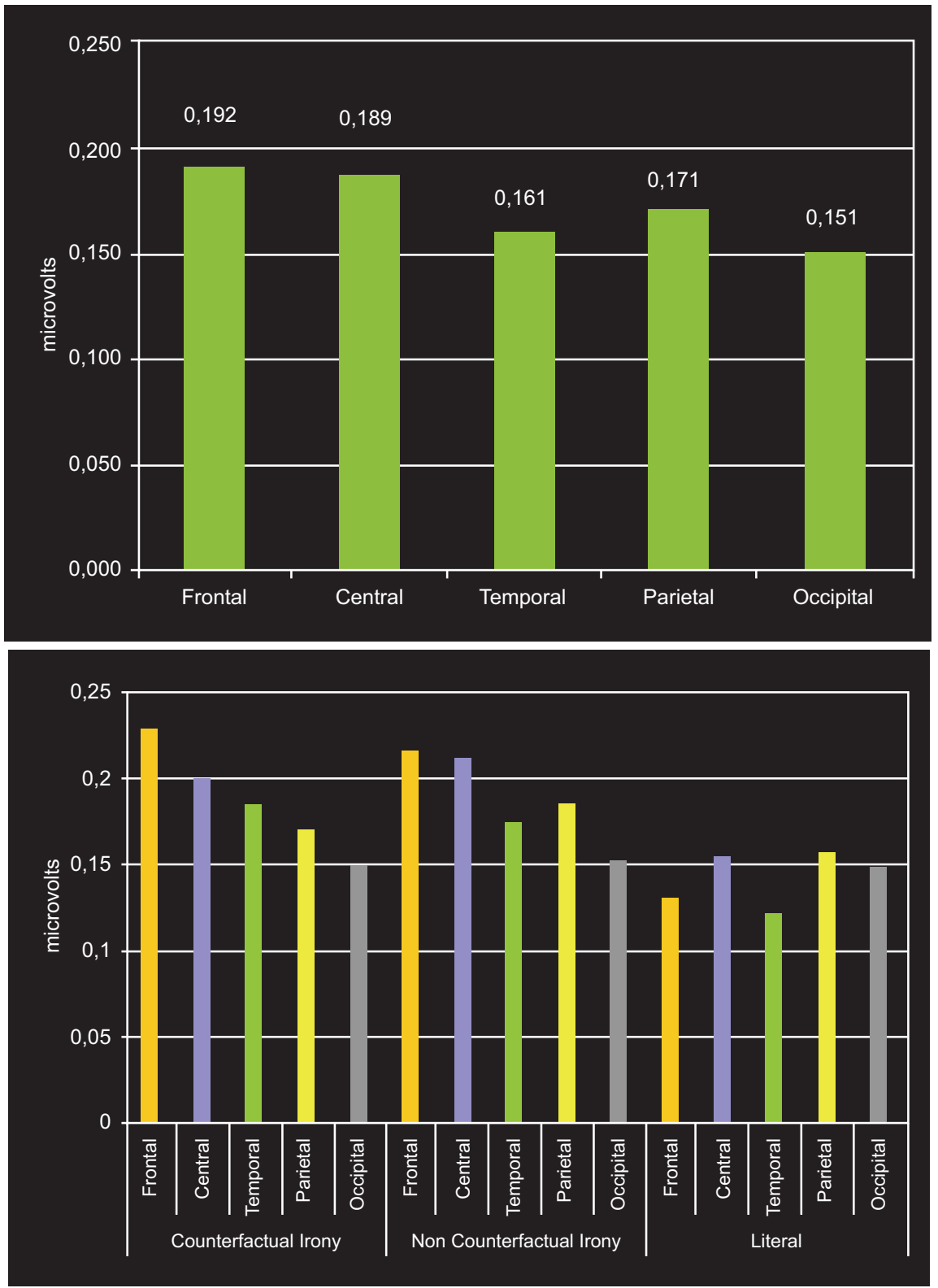

Fig. (4). N400 peak amplitude in different cortical areas across the conditions (a) and as a function of the type of sentence and of localization (b).

more of the cognitive resources. Following a Parallel Access model, this requirement can be attributed to a higher complexity of ironic processing due to an effort to select the ironic meaning against other meanings concurrently activated. In alternative, the increase of the N400 component in our data set could be attributed to the low aptness of our ironic stimuli, since prosody was the only relevant contextual information subjects were given. In other words, we could interpret the tendency relieved in ironic processing as an extra-effort required by the subjects to reconstruct the ironic meaning. In fact, other studies [43] have associated this increase with a higher requirement for the cognitive system in order to elaborate ironic stimuli and this could be due to the nature of ironic meaning that is somehow inconclusive or manifold and therefore makes the closure process more difficult.
In this study, we did not dispose of reading times that could help to clarify this point about the actual complexity of ironical decoding, giving more information about the actual complexity of irony elaboration. So we prefere to let it as an hypothesis that will need further investigations to be endorsed.

Second, the larger activation of frontal-central areas is congruent with neuropsychological data that show the importance of frontal areas in irony comprehension [60-63]. Frontal areas have been associated with intentions decoding, therefore higher activation of this area in the early stages of irony processing seems to indicate that the decoding of the ironic intention occurs early on and is involved in semantic processes. In fact, neuropsychological studies [62, 64, 65] affirm that irony elaboration is a complex process where the decoding of ironic intention indexes (mainly nonverbal) occurs in the first phases of sentence interpretation, as the early 
activation of frontal areas suggests, and functions as an heuristic for meaning construction.

Obviously these tendencies would need further exploration in order to be confirmed.

\section{CONCLUSION}

In conclusion, our data showed that irony is not to be considered as a semantic anomaly, but instead as a complex pragmatic phenomenon originating in the interaction between verbal and non verbal components.

We think that these findings could provide interesting hints to be applied in the field of clinical neuropsychology, where much research is done with individuals presenting formal linguistic skill deficits and general pragmatic impairments. That is the case, for example, of autism, where individuals with spectrum disorders frequently misinterpret the intend meaning of nonliteral remarks due to their difficulties in theory of mind tasks $[67,68]$ associated with difficulties in perceiving, using and interpreting prosodic cues [69]. Our data seem to confirm that prosodical and contextual information, rather than linguistic/semantic information are relevant in the understanding of irony and this could be taken as a confirmation on healthy people of clinical research observation.

Obviously, further studies integrating electrophysiological and behavioural measures could provide a clarification on the processes - and their order of complexity - involved in ironic meaning processing. Furthermore, we believe that later time window, following the N400 interval, could be more suggestive of specific irony-related components (see also [54, 66]). Again, further investigation are required.

\section{REFERENCES}

[1] Grice P. Logic and conversation. In: Cole P, Morgan JL, Eds. Syntax and semantics 3: Speech acts. Academic Press 1975; pp. 41-58.

[2] Searle JR. Speech acts: An essay in the philosophy of language. Cambridge, England: Cambridge University Press 1969.

[3] Kumon-Nakamura S, Glucksberg S, Brown M. How about another piece of pie: the allusional pretense theory of discourse irony. J Exp Psychol Gen 1995; 124: 3-21.

[4] Clark H, Gerrig R. On the pretense theory of irony. J Exp Psychol Gen 1984; 113: 121-26.

[5] Sperber D, Wilson D. Relevance: communication and cognition. Oxford, England: Blackwell 1986.

[6] Attardo S. Irony as relevant inappropriateness. J Pragmat 2000; 32 : 793-826.

[7] Giora, R. (1995). On irony and negation. Discour Process 19, 239264.

[8] Giora R, Fein O, Schwartz T. Irony: graded salience and indirect negation. Metaphor Symbol 1998; 13: 83-101.

[9] Gibbs RW. The poetics of mind: figurative thought and figurative language. San Diego, CA: Academic Press 1994.

[10] Kihara Y. The mental space structure of verbal irony. Cognitive Linguistics 2005; 16: 513-530.

[11] Ritchie D. Frame-shifting in humor and irony. Metaphor Symbol 2005; 20: 275-294.

[12] Colston HL. Contrast and assimilation in verbal irony. J Pragmat 2002; 34: 111-142.

[13] Anolli L, Ciceri R, Infantino MG. Behind dark glasses: Irony as a strategy for indirect communication. Genet Social Gen Psychol 2002; 128: 76-95.

[14] Gibbs RW, Colston HL, Eds. Irony and language and thought. A cognitive science reader. New York, NY: Erlbaum 2007b.

[15] Kreuz RJ. The use of verbal irony: Cues and constraints. In: Mio JS, Katz AN, Eds. Metaphor: Implications and applications. Lawrence Erlbaum 1996: 32-53.
[16] Colston HL, O'Brien J. Contrast and pragmatics in figurative language: Anything understatement can do, irony can do better. $\mathrm{J}$ Pragmat 2000; 32: 1557-1583.

[17] Utsumi A. Verbal irony as implicit display of ironic environment: Distinguishing ironic utterances from nonirony. J Pragmat 2000; 32: 1777-1806.

[18] Austin JL. How to do things with words: The William James lectures delivered in Harvard University in 1955. Oxford, England: Clarendon 1962.

[19] Searle JR. A classification of illocutionary acts. Lang Soc 1976; 5: $1-23$.

[20] Sperber D, Wilson D. Verbal Irony: Pretense or echoic mention? J Exp Psychol Gen 1984; 113: 130-136.

[21] Kreuz RJ, Glucksberg S. How to be sarcastic: The echoic reminder theory of verbal irony. J Exp Psychol Gen 1989; 118: 374-386.

[22] Anolli L, Ciceri R, Infantino MG. Irony as a game of implicitness: Acoustic profiles of ironic communication. J Psycholinguist Res 2000; 29: 275-311.

[23] Attardo S, Eisterhold J, Hay J, Poggi I. Multimodal markers of irony and sarcasm. Humor 2003; 16: 243-260.

[24] Long DL, Graesser AC. Wit and humour in discourse processes. Discour Process 1988; 11: 35-60.

[25] Giora R. On our mind: Context, salience and figurative language. New York, NY: Oxford University Press 2003.

[26] Gibbs RW. A new look at literal meaning in understanding what is said and implicated. J Pragmat 2002; 34: 457-486.

[27] Clark HH, Lucy P. Understanding what is meant from what is said: A study in conversationally conveyed requests. J Verbal Learn Verbal Behav 1975;14: 56-72.

[28] Gibbs RW. Interpreting what speakers say and implicate. Brain Lang 1999; 68: 466-485.

[29] Giora R. On the priority of salient meanings: Studies of literal and figurative language. J Pragmat 1999; 31: 919-929.

[30] Giora R., Fein O. Irony comprehension: The graded salience hypothesis. Humor Int J Humor Res 1999; 12: 425-436.

[31] Giora R, Fein O. Irony: Context and salience. Metaphor Symbol 1999b; 14: 241-257.

[32] Dews S, Winner E. Obligatory processing of literal and nonliteral meanings in verbal irony. J Pragmat 1999; 31: 1579-1599.

[33] Schwoebel J, Dews S, Winner E, Srinivas K. (2000). Obligatory processing of the literal meaning of ironic utterances: Further evidence. Metaphor Symbol 15, 47-61.

[34] Giora R, Fein O, Laadan D, et al. Expecting irony: Context versus salience-based effects. Metaphor Symbol 2007; 22: 119-146.

[35] Gibbs RW, O'Brien JE, Doolittle S. Inferring meanings that are not intended: Speakers' intentions and irony comprehension. Discour Process 1995; 20: 187-203.

[36] Ivanko SL, Pexman PM. Context incongruity and irony processing. Discour Process 2003; 35: 241-279.

[37] Kutas M, van Petten CK. Psycholinguistics electrified: Eventrelated brain potential investigations. In: Gernsbacher MA, Ed. Handbook of psycholinguistics, Academic Press 1994; pp. 83-143.

[38] Coulson S. Electrophisiology and pragmatic language comprehension. In: Sperber D, Noveck IA Eds. Experimental pragmatics, Palgrave 2004; pp. 187-206.

[39] Coulson S, Van Petten C. Conceptual integration and metaphor: An event-related potential study. Memory Cogn 2002; 30: 958-68.

[40] Pynte J, Besson M, Robichon. FH, Poli J. The time-course of metaphor comprehension: An event-related potential study. Brain Lang 1996; 55: 293-316.

[41] Balconi M, Tutino S. A fighter is a lion. Neuropsychological and cognitive processes in decoding a metaphor: An analysis through ERPs. J Int Neuropsychol Soc Suppl 2006; 12: 88.

[42] Balconi M, Tutino S. The iconic representation of metaphor: An event-related potentials (ERPs) analysis of figurative language. Neuropsychol Trends 2007; 2: 41-61.

[42] Coulson S, Wu YC. Right hemisphere activation of joke-related information: An event-related brain potential study. J Cogn Neurosci 2005; 17: 494-506.

[43] Cornejol C, Simonetti F, Aldunate N, Ibanez A, Lopez V, Melloni L. Electrophysiological evidence of different interpretative strategies in irony comprehension. J Psycholinguist Res 2007; 36: 411430.

[44] Balconi M, Amenta S. Neuropsychological processes in verbal irony comprehension: An event-related potentials (ERPs) investigation. J Int Neuropsychol Soc 2007; 13: (Suppl 2), 77. 
[45] Balconi M, Amenta S. Dalla pragmatica alla prospettiva neuropragmatica. In: Balconi M, Ed. Neuropsicologia della comunicazione, Springer-Verlag 2008; pp. 163-181.

[46] Rugg MD, Coles MGH. The ERP and cognitive psychology: Conceptual issues. In: Rugg M, Coles M, Eds. Electrophysiology of mind, Oxford University Press 1995; pp. 1-26.

[47] Kutas M, Hillyard SA. Reading senseless sentences: Brain potentials reflect semantic incongruity. Science 1980; 207: 203-205.

[48] Kutas M, Hillyard S. Brain potential during reading reflect word expectancies and semantic association. Nature 1984; 307: 161-163.

[49] Coulson S, King JW, Kutas M. Expect the unexpected: Eventrelated brain responses to morphosyntactic violations. Lang Cogn Process 1998; 13: 21-58.

[50] Balconi M, Pozzoli U. N400 and P600 or the role of the ERP correlates in sentence comprehension: Some applications to the Italian language. J Gen Psychol 2004; 131: 268-303.

[51] Balconi M, Pozzoli U. Comprehending semantic and grammatical violations in Italian: N400 and P600 comparison with visual and auditory stimuli. J Psycholinguist Res 2005; 34: 71-98.

[52] Kuperberg GR, Holcomb PJ, Sitnikova T, Greve, D, Dale A, Caplan D. Distinct patterns of neural modulation during the processing of conceptual and syntactic anomalies. J Cogn Neurosci 2003; 15: 272-293.

[53] Nieuwland MS, Van Berkum JJA. When peanuts fall in love: N400 evidence for the power of discourse. J Cogn Neurosci 2006; 18: 1098-1111.

[54] Regel S, Gunter TC, Friederici AD. Processing of ironic and nonironic sentences examined with ERPs. Proceedings of the 19th Annual CUNY Conference on Human Sentence Processing, 2006.

[55] Kreuz RJ, Roberts RM. Two cues for verbal irony: Hyperbole and the ironic tone of voice. Metaphor Symbol Act 1995; 10: 21-30.

[56] Jaspers HH. The ten-twenty electrode system of International Federation EEG. Clin Neurophysiol 1958; 10: 371-375.

[57] Giora R, Federman S, Kehat A, Fein O, Sabah H. Irony aptness. Humor 2005; 18: 23-39.
[58] Kreuz RJ. The production and processing of verbal irony. Metaphor Symbol 2000; 15: 99-107.

[59] Colston HL. On necessary conditions for verbal irony comprehension. Pragmat Cogn 2000; 8: 277-324.

[60] Gallagher HL, Happé F, Brunswick N, Fletcher PC, Frith U, Frith CD. Reading the mind in cartoons and stories: An fMRI study of "theory of mind" in verbal and nonverbal tasks. Neuropsychologia 2000; 38: 11-21

[61] Stuss DT, Gallup GG Jr, Alexander MP. The frontal lobes are necessary for theory of mind. Brain 2001; 124: 279-286.

[62] Ting Wang A, Lee SS, Sigman M, Dapretto M. Developmental changes in the neural basis of interpreting communicative intent. Scan 2006; 1: 107-121.

[63] Shamay-Tsoory SG, Tomer R, Aharon-Peretz J. The neuroanatomical basis of understanding sarcasm and its relationship to social cognition. Neuropsychology 2005;19: 288-300.

[64] Uchiyama H, Seki A, Kageyama $\mathrm{H}$, et al. Neural substrates of sarcasm: A functional magnetic-resonance imaging study. Brain Res 2006; 1124: 100-110.

[65] Wakusawa, K, Sugiura M, Sassa Y, et al. Comprehension of implicit meanings in social situations involving irony: A functional MRI study. NeuroImage 2007; 37: 1417-1426.

[66] Regel S, Gunter TC, Friederici AD. Late positivity or late positivities? A comparison of P600 effects elicited by morphosyntactic and semantic-pragmatic anomalies. Proceedings of the Cognitive Neuroscience Society Annual Meeting; 2007.

[67] Ting Wang A, Lee SS, Sigman M, dapretto M. Neural basis of irony comprehension in children with autism: The role of prosody and context. Brain 2006; 129: 932-943

[68] Martin I, McDonald S. An exploration of causes of non-literal language problems in individuals with Asperger syndrome. J Autism Dev Disord 2004; 34: 311-328

[69] Paul R, Augustryn A, Klin A, Volkmar FR. Perception and production of prosody by speakers with autism spectrum disorders. Autism Dev Disord 2005; 35: 205-220

(c) Balconi and Amenta; Licensee Bentham Open.

This is an open access article distributed under the terms of the Creative Commons Attribution License (http://creativecommons.org/licenses/by/2.5/), which permits unrestrictive use, distribution, and reproduction in any medium, provided the original work is properly cited. 